\title{
AVALIAÇÃO DOS DOCENTES E FUTUROS DOCENTES, QUANTO AO CONHECIMENTO E UTILIZAÇÃO DE MÍDIAS INTERATIVAS NAS PRÁTICAS PEDAGÓGICAS
}

\author{
D. M. M. SOUSA ${ }^{1 *}$ e I. V. EGÍDIO² \\ ${ }^{1}$ Universidade Federal do Semi-Árido - UFERSA \\ ${ }^{2}$ Universidade Federal da Paraíba - UFPB \\ daniellemariem@yahoo.com.br
}

Artigo submetido em fevereiro/2015 e aceito em dezembro/2015

DOI: $10.15628 /$ holos.2016.2808

\section{RESUMO}

Os recursos midiáticos surgiram na educação para dar amplitude às novas formas de ensinar e aprender, auxiliando com rapidez na busca pelas informações, nesse sentido, o presente trabalho objetivou avaliar os docentes e os futuros docentes dos cursos de Licenciatura à distância, quanto ao conhecimento e a utilização das Mídias Interativas em suas práticas pedagógicas. Trata-se de um estudo de natureza qualitativa e quantitativa, e conta com a aplicação de questionário com questões objetivas e subjetivas como instrumento para coleta de dados. Para tal, analisa a percepção dos professores que lecionam em uma Escola Estadual de Ensino Fundamental, no município de Itaporanga, Paraíba e os alunos das Licenciaturas da Educação à Distância (EAD) da Universidade Federal da Paraíba (UFPB), com Polo de Apoio Presencial no mesmo município, no que tange ao conhecimento e utilização tanto dos docentes que estão em exercício quanto aos futuros docentes (atuais discentes), na perspectiva do uso dos recursos midiáticos nas práticas pedagógicas. Com a pesquisa, pode-se concluir que, é notória as dificuldades que os docentes possuem na utilização dos recursos tecnológicos, gerando a insegurança e o medo, o que os levam muitas vezes a sua não utilização, pois é percebido que alguns alunos têm mais conhecimento sobre o uso dos recursos que os próprios professores. Em contrapartida é perceptível à motivação, o domínio e a facilidade que os alunos da EAD têm na utilização dos recursos, o que os diferencia dos docentes atuais, pois usufruem de recursos tecnológicos diversos de aprendizagem.

PALAVRAS-CHAVE: Tecnologias de Informação e Comunicação, Mídias Interativas, Práticas Pedagógicas.

\section{EVALUATION OF TEACHERS AND FUTURE TEACHERS, AS TO THE KNOWLEDGE AND USE OF INTERACTIVE MEDIA IN EDUCATIONAL PRACTICES}

\begin{abstract}
Resources media emerged in education to give breadth to new ways of teaching and learning, helping to speed the search for information, in this sense, the present study aimed to evaluate teachers and future teachers of courses of Degree in the distance, as the knowledge and the use of interactive media in their teaching practices. It is a study of qualitative and quantitative nature, and includes the application of a questionnaire with objective and subjective questions as a tool for data collection. To that end, it analyzes the perception of teachers who teach in a state of Basic Education School in the municipality of Itaporanga, Paraíba and students of Distance Education of Undergraduate (EAD) of the Federal University of Paraíba (UFPB) with Polo Classroom
\end{abstract}

Support in the same municipality, with respect to knowledge and use of both teachers who are acting as the future teachers (current students), from the perspective of the use of media resources in pedagogical practices. Through research, we can conclude that is notorious difficulties that teachers have the use of technological resources, creating insecurity and fear, leading them often to no use as it is realized that some students have more knowledge about the use of resources that teachers themselves. In contrast is noticeable motivation, mastery and ease students EAD have the use of resources, which differentiates them from current teachers as enjoy various technological resources for learning.

KEYWORDS: Information and Communication Technologies, Interactive Media, Pedagogic Practices. 


\section{INTRODUÇÃO}

Os recursos midiáticos surgiram na educação para dar amplitude às novas formas de ensinar e aprender, proporcionando o desenvolvimento de habilidades e competências, facilitando o processo de comunicação e interação entre professor/aluno/conhecimento/ tecnologia, auxiliando com rapidez na busca pelas informações. O Estágio Supervisionado é um componente curricular importante na matriz curricular dos cursos de licenciatura, e tem por objetivos a construção da identidade profissional, a reflexão sobre as práticas pedagógicas, além de favorecer a descoberta, por ser um processo dinâmico de aprendizagens em diferentes áreas de atuação do campo profissional, possibilitando assim, consolidar a profissionalização. Segundo Alarcão (1996), o estágio deve ser considerado tão importante como os outros conteúdos curriculares.

O docente contemporâneo deve utilizar os recursos tecnológicos disponíveis, como aliados em sua tarefa de facilitador de aprendizagens, quebrando assim, as barreiras do tradicionalismo e superando os obstáculos, buscando métodos eficazes com o intuito de promover um ensinoaprendizagem de qualidade.

Porém, é interessante destacar, conforme destaca Araújo (2004), que não basta introduzir as mídias na educação apenas para acompanhar o desenvolvimento tecnológico ou usá-las como forma de passar o tempo, mas que haja uma preparação para que os professores tenham segurança, não só em manuseá-las, mas principalmente em saber utilizá-las de modo seguro e satisfatório, transformando-as em aliadas para a aprendizagem de seus alunos.

O papel do docente é uma tarefa desafiadora, que exige empenho, persistência, paciência e crença, implicando assim, no desenvolvimento das questões educacionais em que pensar, refletir, planejar e executar sejam pontos de partida norteados por princípios que atendam aos objetivos voltados para a melhoria da qualidade de ensino. Segundo Freire (1979), a ação docente é a base de uma boa formação escolar e contribui para a construção de uma sociedade pensante.

Diante desse contexto, em uma sociedade globalizada e com os constantes avanços tecnológicos, vem à necessidade de incluir e adaptar a educação, recursos metodológicos que sejam capazes de auxiliar na construção das mudanças necessárias à melhoria da qualidade do ensino.

Para alcançar a essência desse fenômeno de pesquisa, foi perguntado aos alunos das Licenciaturas em Educação à Distância (EAD) e aos professores de uma escola municipal: Qual a importância das mídias interativas nas Práticas Pedagógicas? E se os professores estão preparados para aliar as Tecnologias da Informação e Comunicação (TIC's) suas práticas pedagógicas?

Dessa forma, o trabalho objetivou avaliar as Mídias Interativas quanto ao conhecimento e a sua utilização nas Práticas Pedagógicas realizadas por discentes dos cursos de Licenciatura à distância, realizando um paralelo de sua utilização, com os docentes em atuação de uma escola municipal. 


\section{MATERIAL E MÉTODOS}

\subsection{Caracterização da pesquisa}

Esta pesquisa foi realizada através de um estudo exploratório, assim como, por meio de uma pesquisa bibliográfica, que, segundo Gil (2008, p.50), “[...] é desenvolvida a partir de material já elaborado, constituído de livros e artigos científicos". Mas, devido à amplitude e complexidade do fenômeno, o estudo exploratório trará à tona uma visão global da problemática pesquisada, assim como esclarece Gonçalves (2007, p.65) quando diz que “[...] a pesquisa exploratória oferece uma visão panorâmica, uma primeira aproximação com determinado fenômeno".

Nesse contexto, a partir dos dados coletados foi realizada uma análise, para que se tenha um olhar mais aguçado no que concerne ao fenômeno referente aos impactos das Mídias Interativas nas práticas pedagógicas dos discentes dos cursos de Licenciatura da UFPB (Universidade Federal da Paraíba) virtual do Polo de Itaporanga - PB, bem como sua utilização por docentes que atuam em uma Escola Estadual de Ensino Fundamental, do mesmo município.

\subsection{Caracterização dos Ambientes da Pesquisa}

O município de Itaporanga está localizado na região Oeste do Estado da Paraíba, limitandose ao Sul com Boa Ventura, Diamante e Pedra Branca; a Oeste São José de Caiana; a Norte com Aguiar e Igaracy; a Nordeste com Piancó e; a Leste com Santana dos Garrotes. No ano de 2010 sua população foi estimada em 23.192 habitantes, com área territorial de 468,060 km² (IBGE, 2010).

A pesquisa foi desenvolvida em dois ambientes, na Escola Estadual de Ensino Fundamental e no Polo de Apoio Presencial de da UFPB Virtual de Itaporanga-PB.

Escola Estadual oferece apenas o Ensino Fundamental I e II e o Ensino Fundamental II na modalidade EJA (Educação de Jovens e Adultos) para aqueles que estão fora da faixa etária de escolarização obrigatória estabelecida pela lei.

A escola conta em 2014 com 378 alunos, distribuídos nos três turnos; manhã, tarde e noite. Conta ainda com uma Gestora e sua vice, não possui supervisor e orientador escolar, nem psicólogo, possuindo atualmente 26 professores todos de Nível superior, com formação pedagógica, mas apenas 19 estão em atividade, os demais estão com readaptação de função por motivos diversos.

O Polo Universitário de Apoio Presencial - UAB (Universidade Aberta do Brasil) de Itaporanga - PB, atende aos seguintes municípios: Itaporanga (sede do Polo), Boa Ventura, Curral Velho, Nova Olinda, Santana dos Garrotes, Diamante, Ibiara, Santana de Mangueira, Santa Inês, Conceição, Bonito de Santa Fé, Cajazeiras, Serra Grande, São José de Caiana, Igaracy, Aguiar, Piancó, Patos e São José de Piranhas.

A inauguração do Polo de Itaporanga foi realizada em 06 de Março de 2008, contando com 150 alunos e 06 tutores distribuídos nos cursos de Matemática, Letras e Pedagogia. Desde então, que começou a efetivar o ensino superior no vale do Piancó. 
Atualmente o Polo conta com 30 tutores distribuídos nos oito cursos ofertados pela UFPB, Letras-Língua Portuguesa, Matemática, Pedagogia, Ciências Naturais, Ciências Agrárias, Ciências Biológicas, Letras-Libras, Computação, dois pela UEPB (Universidade Estadual da Paraíba) Administração pública e Geografia e uma Pós-Graduação pelo IFPB (instituto Federal da Paraíba): Especialização em Gestão Pública Municipal e conta com total de 1.239 alunos, aproximadamente, no ano de 2014.

\subsection{Sujeitos da pesquisa}

A pesquisa foi realizada com 41 discentes das Licenciaturas da EAD, sendo 10 do curso de Pedagogia, 10 de Ciências Naturais, 6 de Ciências Agrárias, 7 de Matemática, 7 de Letras - Língua Portuguesa e 1 de Letras-Libras, bem como, com 16 docentes da Escola Estadual, onde todos lecionam no Ensino Fundamental I e II.

$\mathrm{Na}$ pesquisa ressalta-se o propósito de analisar o que os alunos das Licenciaturas em EAD pensam sobre a utilização das Mídias Interativas, assim como a competência dos docentes, quanto à utilização das Tecnologias de Informação e Comunicação pelos educadores da Escola Estadual, averiguando se estes possuem habilidades para a inserção dessas tecnologias nas Práticas Pedagógicas.

\subsection{Instrumento e coleta de dados da pesquisa}

A pesquisa foi desenvolvida dentro da perspectiva quantitativa e qualitativa. Através da aplicação de questionários semiestruturados, com 10 questões objetivas e subjetivas destinados aos alunos das Licenciaturas da UFPB Virtual e professores da Escola Estadual de Ensino Fundamental. Conforme afirma Cervo et al (2007), o questionário o possui a vantagem, que os respondentes se sentem mais confiantes, dado o anonimato, o que possibilita coletar informações e respostas mais reais.

\section{RESULTADOS E DISCUSSÃO}

Segundo descrito anteriormente, ressalta-se que os discentes foram escolhidos aleatoriamente, dentre os que já haviam cursado disciplinas práticas, tais como Estágio Supervisionado, pertencentes as Licenciaturas ofertadas Pela Ensino à Distância (EAD) do Polo de Apoio Presencial de Itaporanga-PB.

3.1 Análise do questionário aplicado aos discentes das Licenciaturas da EAD do Polo de Itaporanga-PB

Foi aplicado um questionário contendo 10 perguntas, para os discentes das Licenciaturas da EAD do Polo de Itaporanga-PB, dos cursos de Pedagogia, Matemática, Ciências Agrárias, Ciências Naturais, Letras-Língua Portuguesa e Letras-Libras.

Na primeira questão, foi perguntado a idade dos discentes, para que se tenha uma ideia da faixa etária dos alunos das Licenciaturas da EAD do Polo de Itaporanga-PB. 
Ao analisar a questão relacionada à idade dos discentes (Figura 1), constatou-se que a média das idades fica entre 18 e 44 anos.

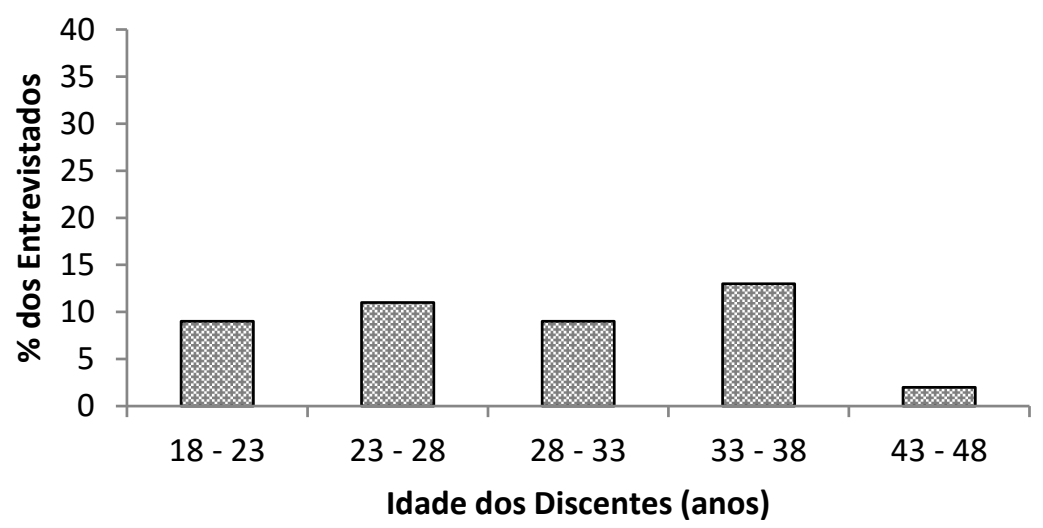

Figura 1: Idade dos discentes das Licenciaturas da EAD, do Polo de Itaporanga-PB.

A Educação à Distância (EAD) tem o importante papel de encurtar distâncias e aproximar as pessoas na busca da aprendizagem. E sendo assim, Sartori e Roesler (2005) traçam o perfil do aluno da EAD sob a sua visão de:

Aquele que não tem condições de frequentar o ensino convencional, o acesso ao ensino, além de ser apontada como uma alternativa de capacitação corporativa e em serviço. A experiência educacional nessa área tem comprovado que seu público-alvo é, em sua grande maioria, o aluno adulto que busca formação pessoal ou progressão profissional (SARTORI e ROESLER, 2005, p. 141).

Foi analisado também o sexo dos discentes, e conforme pode ser observado na Figura 2 que, dos $100 \%$ dos discentes entrevistados, $80,50 \%$ são do sexo feminino e apenas $19,50 \%$ do sexo masculino.

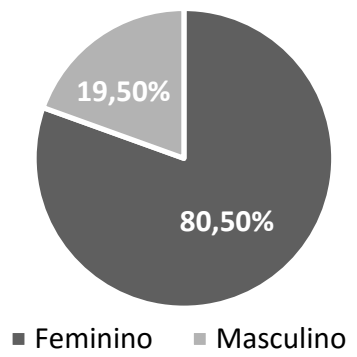

Figura 2: Sexo dos discentes das Licenciaturas da EAD do Polo de Itaporanga - PB.

Quando questionados qual o curso e o período que estão cursando, dos $100 \%$ entrevistados, $17 \%$ estão cursando Pedagogia e estão entre 70 e 8 o período, $24 \%$ estão cursando Licenciatura em Ciências Naturais entre os períodos 5ㅇ, 6으, 7으 e 8‥ Outros $15 \%$ estão cursando

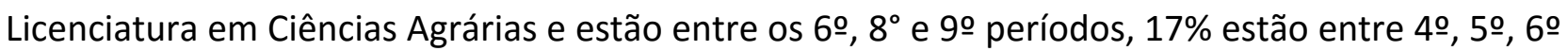
e 70 períodos do curso de Matemática, $17 \%$ estão cursando Licenciatura em Letras - Língua Portuguesa nos períodos compreendidos entre 4으, 5ㅇ, 7으 e 8으 e apenas $3 \%$ dos discentes questionados estão no 8 o período do curso de Letras - Libras. 
Quando questionados se os discentes possuem outra graduação além da que está em curso (Figura 3), dos $100 \%$ entrevistados, apenas $18 \%$ possuem outra graduação, para os demais, ou seja, para $82 \%$ discentes, está é a primeira graduação.

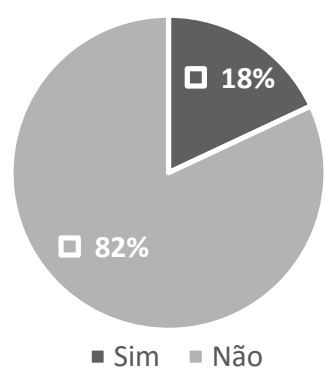

Figura 3: Realização de uma outra graduação pelos discentes das Licenciaturas da EAD, do Polo de Itaporanga-PB.

Quando indagados se consideram importante a utilização dos recursos midiáticos nas práticas pedagógicas, 92,70\% disseram achar importante a utilização de tais recursos, e apenas 7,30\% disseram não achar importante, conforme pode ser observado na Figura 4.

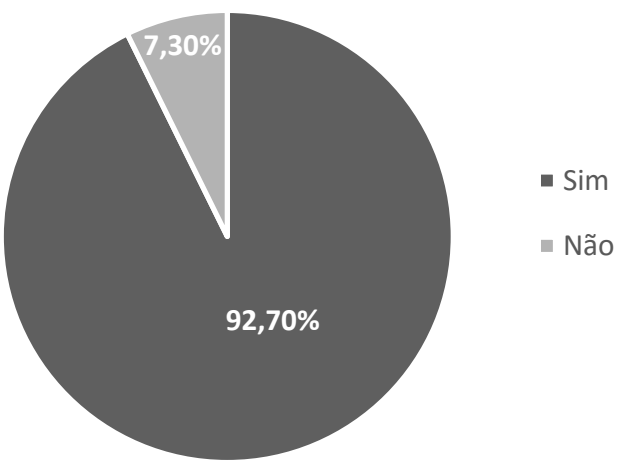

Figura 4: Importância da utilização dos recursos midiáticos nas Práticas Pedagógicas para os discentes das Licenciaturas da EAD, do Polo de Itaporanga-PB.

Sendo assim, fica clara a importância e a necessidade de aliar os recursos midiáticos ao ensino-aprendizagem, visando dessa forma, enriquecer a construção do conhecimento, além de inovar e dinamizar as aulas.

De acordo com Straub (2009, p. 60):

A construção do conhecimento do aluno deve ocorrer por meio de um processo interativo deste com o professor, no qual o professor será o mediador do processo ensino-aprendizagem através da midiatização das tecnologias de informação e de comunicação, principalmente o computador e a internet.

A indagação seguinte afere se os docentes que estão em sala de aula, estão preparados para aliar as TIC's (Tecnologias de Informação e Comunicação) as suas práticas pedagógicas. Entre os entrevistados, $18 \%$ acreditam que sim, e $82 \%$ acreditam que os docentes não estão preparados (Figura 5). 


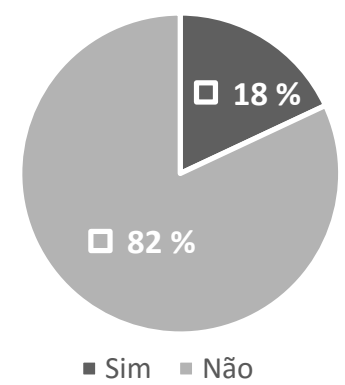

Figura 5: Preparação dos docentes para aliar as TIC's (Tecnologia da Informação e Comunicação) as suas práticas pedagógicas, segundo os discentes das Licenciaturas da EAD do Polo de Itaporanga-PB.

É importante salientar que há uma grande necessidade de se aplicar novas tecnologias em sala de aula, porém os professores devem ser capacitados para usufruir desses equipamentos para a melhoria do ensino e aprendizagem de seus alunos. As tecnologias são criadas para facilitar a vida dos seres humanos e levá-los ao progresso.

Segundo Oliveira (1996), ainda, existe entre os educadores a percepção de que a escola está congelada, pois em vez de estimular o uso das novas tecnologias faz crítica a introdução das mesmas.

Quando indagados se como futuros docentes pretendem fazer uso das mídias em suas aulas? As respostas foram unânimes, onde $100 \%$ dos questionados afirmaram que sim.

As mídias são um conjunto de instrumentos oportunos para dar vida às novas diretrizes do sistema educacional. E o aluno do ensino à distância em especial, sabe da importância destes na sua formação. Diante disso, o futuro docente saberá utilizar estes recursos como meio de promover a aprendizagem.

Para Haetinger (2005) o aluno através destas ferramentas, as novas tecnologias, deve se comprometer muito mais com o aprendizado, o que não acontecia com o ensino tradicional, de apenas recepção de conteúdos. Portanto, o futuro docente deve se empenhar e capacitar-se para adquirir domínio e manusear os recursos tecnológicos a favor de um ensino-aprendizagem de qualidade.

Pois, a tecnologia na educação almeja uma amplitude maior que envolva novas formas de ensinar e de aprender inerentes com a discussão da sociedade do conhecimento, caracterizada pelos princípios da diversidade, da integração e da complexidade.

Foi perguntado aos discentes se nas escolas onde realizaram os Estágios Supervisionados possuem ou não recursos midiáticos disponíveis, onde $41,50 \%$ responderam sim, e 58,50\% que não conforme pode ser observado na Figura 6: 


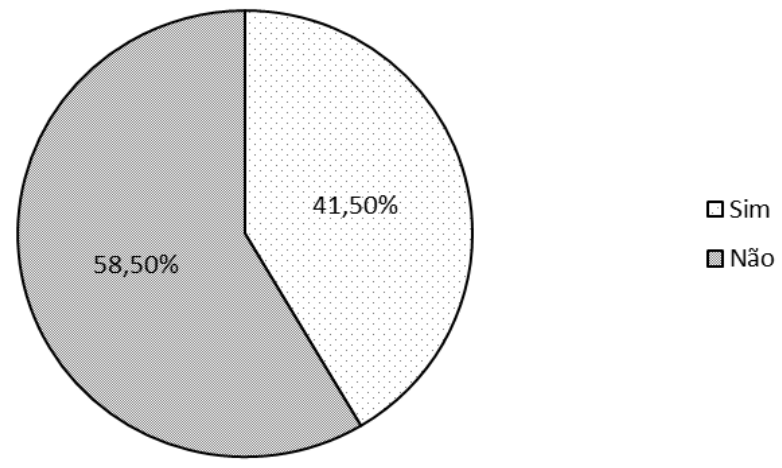

Figura 6: Presença de recursos midiáticos disponíveis para a realização das aulas, onde os discentes das Licenciaturas da EAD do Polo de Itaporanga-PB, realizam o Estágio Supervisionado.

Dessa forma, pode-se constatar ainda a precariedade das instituições de ensino, diante da necessidade da inserção dos recursos midiáticos no ensino-aprendizagem, já que estes contribuem de forma significativa no processo de ensino-aprendizagem, além de inovar e tornar as aulas menos cansativas e enfadonhas.

Uma das mais importantes funções dos educadores é despertar o interesse e desenvolver as habilidades de seus educandos.

Segundo Martins (2007, p. 204)

As tecnologias atuais permitem a criação de situações de aprendizagens ricas, complexas e diversificadas que contribuem para o indivíduo manifestar sua individualidade e criatividade e estabelecer interações de forma integral e eficiente.

Na décima e última questão foi perguntado aos discentes quais as principais mídias que estes utilizaram em seus estágios. E $83 \%$ dos entrevistados, ficaram divididos entre o uso de cartazes, vídeos, notebook e datashow, 15\% fizeram uso de jogos educativos e dinâmicas de grupo e apenas $2 \%$ disse que fez uso de experimentos durante o período de estágio supervisionado.

De acordo com Kenski (2008 p. 23),

As novas tecnologias de informação e comunicação, caracterizadas como midiáticas, são, portanto, mais do que simples suportes. Elas interferem em nosso modo de pensar, sentir, agir, de nos relacionarmos socialmente e adquirirmos conhecimentos. Criam uma nova cultura e um novo modelo de sociedade.

Nesse sentido, percebe-se que os futuros docentes, sabem da importância e necessidade de aliar os recursos midiáticos as suas práticas pedagógicas, pois enquanto aluno EAD, são conscientes de quão importante são esses recursos para sua formação.

3.2 Análise do questionário aplicado aos docentes da Escola Estadual de Ensino Fundamental

Para os docentes da Escola Estadual de Ensino Fundamental, foi aplicado um questionário contendo 10 perguntas. O primeiro questionamento teve como objetivo avaliar a sua faixa etária. 


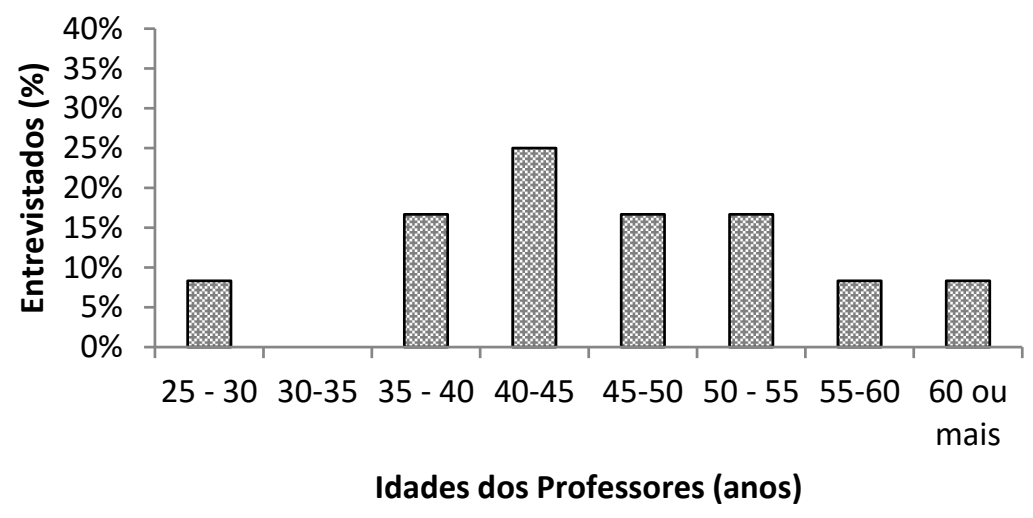

Figura 7. Quanto à Idade dos docentes da Escola Estadual de Ensino Fundamental, Itaporanga-PB.

Como pode ser observado na Figura 7, a maioria dos docentes possui faixa etária acima dos trinta anos de idade. Mas, o que é importante analisar, não é apenas a idade dos mesmos, mas a formação acadêmica e as teorias que embasam suas práticas pedagógicas, como também os cursos que os capacitam para atuar com as Tecnologias da Informação e Comunicação no ambiente escolar e em outras áreas que auxiliem no desenvolvimento das habilidades e competências dos discentes. Com relação ao sexo dos entrevistados, de acordo com a Figura 8, verificou-se que, dos docentes entrevistados $93,75 \%$ são do sexo feminino e apenas $6,25 \%$ do sexo masculino.

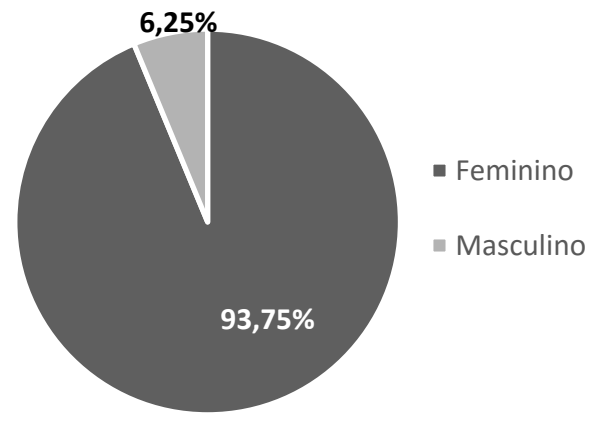

Figura 8. Sexo dos docentes entrevistados na Escola Estadual de Ensino Fundamental Simeão leal, Itaporanga-PB.

Pode-se perceber que, é superior o número de docentes do sexo feminino, estes ganharam espaço no trabalho, lutaram e conquistaram seus espaços, mostrando suas competências e habilidades na tarefa de docente.

Nesse sentido, Costa (1995 p.162) afirma que,

a docência está cada vez mais regulamentada, normatizada e menos autônoma, propiciando o afastamento dos homens que viam no ensino flexibilidade e informalidade que os permitia articula-lo com outras ocupações. Este é mais um fato que reforça o que se convencionou dizer sobre as mulheres que elas são mais sujeitas e acostumadas ao controle, às mulheres se adaptaram com mais facilidade às novas características da ocupação.

Foi indagado aos docentes o tempo que os mesmos exercem à docência, e conforme pode ser observado na Figura 9, grande parte dos mesmos (aproximadamente 40\%) atuam entre 5 a 10 
anos, chegando até aos 30 anos de exercício do magistério (aproximadamente 15\%). É importante ressaltar que dos $100 \%$ entrevistados, $12 \%$ são professores de Educação Física, $19 \%$ de Língua Portuguesa, 12\% de Geografia, 13\% de Ciências, 19\% lecionam Matemática, 6\% Educação Artística, 13\% História e 6\% Língua Inglesa.

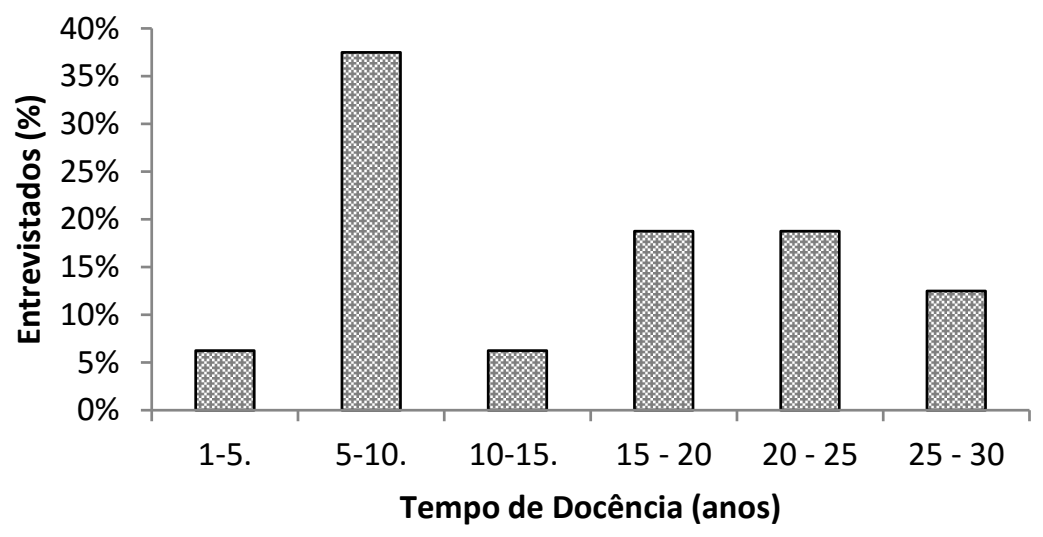

Figura 9: Tempo de docência dos docentes da Escola Estadual de Ensino Fundamental Simeão Leal, Itaporanga-PB.

Quando indagados se possui ou não outra graduação (Figura 10), 62,50\% dos entrevistados, possuem mais de uma graduação, e $37,50 \%$ possuem somente uma graduação.

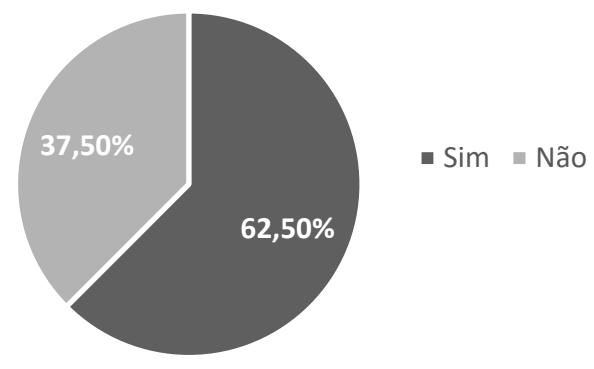

Gráfico 10: Docentes que possuem outra graduação, na Escola Estadual de Ensino Fundamental Simeão Leal, Itaporanga-PB.

Com essa informação percebe-se que a maioria dos licenciados da Escola Estadual possuem mais de uma graduação e sendo assim, pode-se afirmar que estes continuam a se capacitar e atualizar, fato que é muito importante na tarefa docente, pois como qualquer outra atividade requer atualização constante.

No questionamento, se os docentes já fizeram ou não algum curso de capacitação na área das TIC's, 62,50\% já fizeram curso na área, e 37,50\% ainda não realizaram nenhum curso (Figura 11).

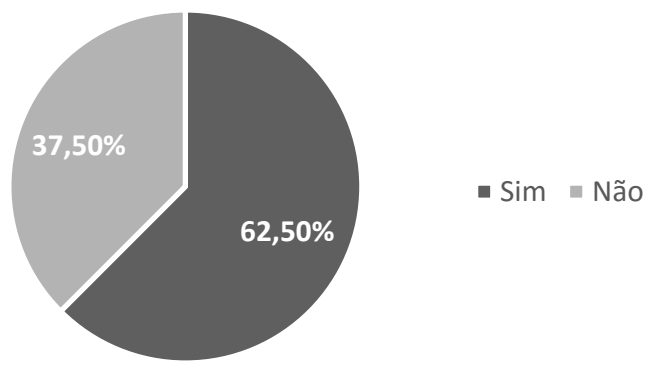


Figura 11: Realização de curso de capacitação na área das TIC's pelos docentes da Escola Estadual de Ensino Fundamental Simeão Leal, Itaporanga - PB.

Diante desse contexto, é notável que grande parte dos docentes buscam capacitar-se para obter o domínio dos recursos tecnológicos, visto que na atualidade, estes são essenciais no processo de ensino-aprendizagem. Como afirma Moran (2014), tudo o que se fizer para inovar na educação nos tempos de hoje será pouco.

Nesse sentido, é primordial buscar a unidade entre teoria e prática no que concerne a inserção das TIC's nas instituições de educação, visando à formação de cidadãos capazes de lidar com os avanços tecnológicos.

A integração de novas tecnologias, possivelmente causa incertezas, colocam em xeque metodologias, que já estão arraigadas e centralizadas no cotidiano das escolas. Isso pode ser um fato positivo, pois exige novas reflexões e novas posturas diante da educação como um todo e do trabalho individual de cada professor, em cada unidade escolar.

$\mathrm{Na}$ Figura 12, foi questionado se os docentes se consideram capacitados para manusear os recursos tecnológicos, onde 56,25\% afirmaram que se encontram capacitados, e $43,75 \%$ relatam que não possuem domínio de tais recursos.

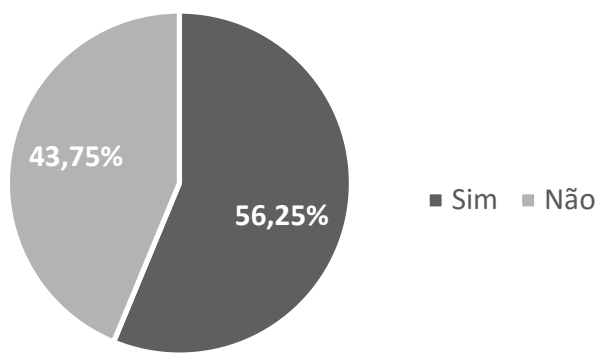

Figura 12: Capacitação dos docentes para manusear corretamente os recursos tecnológicos durante as aulas na Escola Estadual de Ensino Fundamental Simeão Leal, Itaporanga-PB.

Grande parte dos docentes afirma que estão capacitados para manusear os recursos tecnológicos, mas apesar de serem ofertados cursos diversos na área das TIC's, com grande frequência, é notório também, que um grande número de docentes ainda não possui domínio desses recursos.

Diante desse contexto, Saviani (1991) ressalta que:

[...] o professor tem que estar capacitado para atuar nestes momentos, e também ter condições de pensá-los no contexto geral do seu trabalho. A educação hoje, já não pode mais manter-se somente como acadêmica ou profissionalizante, por isso necessitamos de professores que conheçam o sistema produtivo e principalmente as inovações tecnológicas (SAVIANI, 1991, p. 18).

Quando indagados se a escola disponibiliza de recursos midiáticos para utilizarem em suas aulas? Os docentes foram unânimes em responder afirmativamente que sim. Com esta informação, fica clara a necessidade de proporcionar aos docentes mais cursos na área das TIC's para que estes possam adquirir domínio e aliar estes na construção da aprendizagem. Visto que, se a Instituição disponibiliza esses recursos, é para serem utilizados em prol de um ensinoaprendizagem significativo. 
$\mathrm{Na}$ questão seguinte, os docentes foram indagados se acreditam ou não que os recursos tecnológicos melhoram a sua prática docente e o aprendizado dos alunos. Onde todos foram unânimes também nesta questão ao responder que os recursos tecnológicos melhoram tanto sua prática docente quanto o aprendizado de seus alunos.

Nesse sentido, fica claro, que $100 \%$ dos docentes acreditam que a utilização dos recursos tecnológicos melhora tanto sua prática docente quanto a aprendizagem dos alunos, pois a tecnologia educacional está presente nas escolas para melhoria do processo ensino aprendizagem, basta, portanto, colocar isso em prática.

Sant'Anna (2004), recomenda que o professor insira os recursos tecnológicos disponíveis para que a informação ganhe vida.

Foi perguntado aos docentes quais as principais mídias que utiliza ou utilizou em sala de aula, apenas $12 \%$ dos docentes relataram que não faz uso de recursos midiáticos, os demais, ou seja, $88 \%$ relataram o uso de: TV, DVD, computador, data show, vídeos, slides e internet.

Segundo Kalinke (1999, p.15)

Os avanços tecnológicos estão sendo utilizados praticamente por todos os ramos do conhecimento. As descobertas são extremamente rápidas e estão a nossa disposição com uma velocidade nunca antes imaginada. A Internet, os canais de televisão a cabo e aberta, os recursos de multimídia estão presentes e disponíveis na sociedade. Estamos sempre a um passo de qualquer novidade. Em contrapartida, a realidade mundial faz com que nossos alunos estejam cada vez mais informados, atualizados, e participantes deste mundo globalizado.

Por último, foi perguntado aos docentes qual a principal problemática da não utilização dos recursos midiáticos em suas aulas? $67 \%$ dos docentes entrevistados destacam que apesar de possuírem curso na área das $\mathrm{TIC}^{\prime}$, existe uma considerável falta de domínio dos recursos tecnológicos e muitas vezes ainda por acreditarem que os alunos têm maior domínio sobre estes recursos que os próprios professores, outros $20 \%$ reclamam da falta de interesse dos alunos e apenas $13 \%$ disse que não encontra nenhum problema para fazer uso dos recursos tecnológicos.

Conforme afirma Valente (1998), o maior obstáculo para a adoção de computadores nas escolas é a falta de capacitação prévia dos professores para saber como utilizar esta nova ferramenta de trabalho e, principalmente, como introduzir o uso do computador no currículo.

\section{CONCLUSÃO}

Este estudo destinou-se à avaliação docentes e os futuros docentes dos cursos de Licenciatura à distância, quanto ao conhecimento e a utilização das Mídias Interativas em suas práticas pedagógicas.

Onde a preocupação primordial foi analisar até que ponto os docentes atuais dominam e utilizam os recursos midiáticos em suas aulas e os futuros docentes, ou seja, os alunos das licenciaturas em Educação à Distância (EAD), o que estes acham da utilização dos recursos midiáticos nas Práticas Pedagógicas. 
Como resultado da investigação, é notório as dificuldades que os docentes possuem na utilização dos recursos tecnológicos, apesar de alguns já terem curso na área da Tecnologia da Informação e Comunicação, mas não possuem o total domínio, que é o mais importante, gerando a insegurança, o medo, o que os levam muitas vezes a não utilização, pois é percebido que alguns alunos têm mais conhecimento sobre o uso dos recursos que os próprios professores.

Não adianta impor o uso de computadores, meios impressos, DVDs entre outros, se o profissional não está apto a lidar com essas novas tecnologias.

É necessário adquirir domínio, utilizar mais os recursos para obter segurança, capacitandose para atuar como docente inovador e dinâmico que o século XXI impõe. Nessa tarefa, o gestor pode e deve intervir, incentivando os docentes a usar e praticar a utilização dos recursos tecnológicos, para poder assim, ganhar segurança e domínio, a fim de aliar estes recursos na construção de uma aprendizagem significativa.

Pois as mídias vieram para dar amplitude às novas formas de ensinar e aprender, e sendo assim, é primordial buscar a unidade entre teoria e prática no que concerne a inserção das TIC's nas instituições de educação, visando à formação de cidadãos capazes de lidar com os avanços tecnológicos.

Em contrapartida é perceptível à motivação, o domínio e a facilidade que os alunos da EAD têm na utilização dos recursos, o que os diferencia dos docentes atuais, pois estudam através da rede mundial de computadores (internet), usufruindo de recursos tecnológicos diversos de aprendizagem.

Espera-se que esta pesquisa possa contribuir para que os professores busquem novas perspectivas, mudanças em suas técnicas educacionais e em seus planejamentos. Oferecendo oportunidades de melhoria das aulas, através da inclusão das mídias interativas nas Práticas Pedagógicas.

\section{REFERÊNCIAS}

1. ALARCÃO, I.(org.). Formação reflexiva de professores estratégias de supervisão. Porto: Porto Editora, 1996.

2. ARAÚJO, M. I. M. Uma abordagem sobre as tecnologias da informação e da comunicação na formação do professor. In: MERCADO, L; KULLOK, M. Formação de professores: política e profissionalização, Maceió, EDUFAL, 2004.

3. CERVO et al. Metodologia científica. São Paulo: Pearson Prentise Hall, 2007.

4. COSTA, M. C. V. Trabalho docente e profissionalismo. Porto alegre: Sulina, 1995.

5. FREIRE, P. Educação como prática da liberdade. 17 ed. Rio de Janeiro: Paz e Terra, 1979.

6. GIL, A.C. Métodos e Técnicas de Pesquisa Social. 6 ed. São Paulo: Atlas, 2008.

7. GONÇALVES, E. P. Conversas sobre iniciação a pesquisa cientifica. Campinas, SP: Editora Alínea, 2007.

8. HAETINGER, M.G. O Universo Criativo da Criança na educação, coleção Criar. v. 03. Rio Grande do Sul, 2005. 
9. IBGE. Censo 2010. Brasília: IBGE, 2010. Disponível em: <http://www. censo2010.ibge.gov.br/dados_divulgados/index.php?uf=23>.

10. KALINKE, M. A. Para não ser um professor do século passado. Curitiba: Gráfica Expoente, 1999.

11. KENSKI, V. M. Educação e tecnologias: O novo ritmo da informação. Campinas, SP: Papirus, 2008.

12. MARTINS, M. C. Integração das mídias e práticas pedagógicas. In: VALENTE, J. A.; ALMEIDA, M. E. B. (Org.). Formação de educadores à distância e integração de mídias. São Paulo: Avercamp, 2007.

13. MORAN, J, M. A integração das tecnologias na educação. Disponível em: 01 abr de 2014.

14. OLIVEIRA, V. B. (Org.). Informática em psicopedagogia. São Paulo: Ed. SENAC, 1996.

15. SANT'ANNA, I.M.; SANT'ANNA, V. M. Recursos educacionais para o ensino: quando e por quê? Petrópolis: Vozes, 2004.

16. SARTORI, A. S.; ROESLER, J. Educação superior à distância: gestão da aprendizagem e da produção de materiais didáticos impressos e on-line. Tubarão: Ed.: Unisul, 2005.

17. SAVIANI, D. Pedagogia Histórico-crítica: Primeiras Aproximações. 3. ed. São Paulo: Cortez, 1991.

18. STRAUB, S. L.W. Estratégias, desafios e perspectivas do uso da Informática na educação realidade na escola pública. Cáceres: Ed. UNEMAT, 2009.

19. VALENTE, J. A. Computadores e Conhecimento: repensando a educação. Campinas: Gráfica Central da UNICAMP/NIED, 1993. 